\title{
WaterBase: SWAT in an Open Source GIS
}

\author{
C. George ${ }^{1}$ and L.F. Leon*,2 \\ ${ }^{1}$ International Institute for Software Technology, United Nations University, Macao, China \\ ${ }^{2}$ Department of Biology, University of Waterloo, Ontario, Canada
}

\begin{abstract}
WaterBase is a project of the United Nations University. Its aim is to advance the practice of Integrated Water Resources Management (IWRM) in developing countries, by providing (a) free, open source tools for modeling and decision support (b) a collection of IWRM resources: web sites, tools, literature, training material, etc. and (c) a community of partners who can provide advice, support, contribute to tools and resources. A first step in the project is a tool to provide Geographic Information System (GIS) support and a setup interface for the Soil and Water Assessment Tool (SWAT). This paper describes the design of this tool, called Map Window SWAT (MWSWAT).
\end{abstract}

\section{INTRODUCTION}

The WaterBase project (http://www.waterbase.org) of the United Nations University is aimed in particular, though not exclusively, at developing countries. Predictive modelling and decision support for water management in developing countries are plagued with a number of related problems such as: lack of money, lack of expertise, inadequate training capacity, and dependence on experts from other countries. At the same time water resources are under increasing pressure and aquatic ecosystems are being damaged by actions of people who lack the resources to explore the consequences of decisions before they are made. WaterBase aims to improve this situation by providing (a) tools for decision support, (b) resources such as web sites, documentation, training material, and case studies, and (c) a community of partners who can advise and support other partners, and who can contribute to the tools and resources.

SWAT (Srinivasan and Arnold, 1994) [1]; (Neitsch et al., 2005) [2], has a substantial reputation as a model to quantify the impact of land management practices in large, complex watersheds, and has been used in many developing countries as well as in its home country, the US. Like other modeling tools, it requires a lot of data about terrain, landuse, soil, and climate. There are two essential components needed to set up SWAT models: (a) a GIS system to support the storage and display of the relevant maps, and to perform the terrain analysis needed to delineate watersheds, to identify the stream reaches and the associated subbasins, etc., and (b) a component that can generate all the files needed by SWAT, partly from the input maps and analyses, and partly by manual editing.

There is a substantial price tag on the current commercial GIS system that is currently used by SWAT. The WaterBase project decided to identify a suitable free, open source GIS system, and then to produce the additional component that would support the generation of SWAT input data. The use of open source is important: it gives users confidence that tools will not suddenly disappear with their original writers, or one day become something you have to pay for, and also

*Address correspondence to this author at the Department of Biology, University of Waterloo, Ontario, Canada; E-mail: Ifleonvi@uwaterloo.ca gives users the possibility of adapting or extending them. This possibility ranges from the localization of the interface to the local language to the adding of significant functionality. The use of open source tools also implies the use of the corresponding open standards, such as those supported by the Open Geospatial Consortium (OGC) [3].

There are a number of open source GIS systems available (OS GIS) [4]. WaterBase eventually chose MapWindow (http://www.mapwindow.com) for three reasons. First, and critical when choosing any open source project, it was under active development. Second, unlike most open source projects, it is native to Microsoft Windows, which is the operating system we expect most of our users to be currently using and accustomed to. Third, it had just been chosen by the Environmental Protection Agency (EPA) in the US as the basis for version 4 of BASINS (EPA-Basins) [5], which gave us confidence in its future support. There were also technical issues to be considered, such as whether MapWindow, could support watershed delineation, and how easy it was to write an extension for it, but technical problems can often be overcome, while the basic issue of whether your chosen GIS system will still be available and supported in 5 years time is the most important issue.

As it happens, MapWindow does have a watershed delineation tool, using the TauDem software (Tarboton, 2001) [6]. In fact Taudem's use of the Dinf approach to slope directions, instead of the normal $D 8$, promised better watershed delineation than found in the current ArcSWAT interface. MapWindow is also intended to be extensible through the use of "plug-in" architecture, so it was in fact technically suitable. So an interface for setting up SWAT was created based on MapWindow, and called MWSWAT. The rest of this paper describes some of the details of MWSWAT and what else needs to be done to provide decision support for IWRM.

\section{DATA SOURCES}

There is a considerable amount of data available on the web, and MWSWAT is designed from the start to take advantage of that issue in mind. In particular it will be delivered along with global data:

$$
\text { 1. DEM maps: SRTM project (SRTM, 2004) [7]. }
$$


Fig. (1). Main Digital Data Pre-Processed in MapWindow.

2. Land: Global Land Cover Facility (Hansen, 1998) [8].

3. Soil maps: FAO (FAO/UNESCO, 2003) [9].

4. Precipitation and temperature data (NCDC) [10].

The increasing availability of such data opens a number of possibilities for its exploitation beyond water resource management. Additionally, users should not be restricted to such data, because where local data exists it will generally be finer grained and more accurate. But at the same time they should not be prevented from doing some simulations even when there is no local data. Fig. (1) shows an example of the main digital source data (DEM, land and soil) being preprocessed in MapWindow, from selection of files, clipping and re-projecting.

\section{DESIGN PHYLOSOPHY}

Setting up a SWAT run is complicated. Generating a thousand input files is not unusual, and so there are a vast number of parameters to consider. The user can therefore easily get lost in the process, and we need to keep a balance between simplicity of the interface and access to everything the user might need to see and perhaps change. The first priority is therefore to try to create a simple model of the process that the users may have in their minds. We based the interface around three basic steps:

1. Watershed delineation.
2. HRU definition.

3. SWAT setup and run.

This overall design concept is clear from the main MWSWAT form. For example Fig. (2) shows the main control form when the first two steps are completed and the third is ready to be started.

Fig. (2). Main MWSWAT Form.

\section{WATERSHED DELINEATION}

Watershed delineation uses a plug-in included in MapWindow as can be seen in Fig. (3). First the digital elevation (DEM) is chosen, and options to burn in existing streams, 
and/or to use a mask for the watershed, may be selected. Then the threshold (minimum area to be designated as drainage for a stream) is chosen. Finally outlets and inlets are selected, either from an existing shapefile, or by creating one interactively.

Fig. (3). MapWindow Watershed Delineation Plug-in.

After the watershed delineation process is completed, all the layers are displayed in the MapWindow view. A delineated watershed is illustrated in Fig. (4) with all the subwatershed notation in place.

\section{HRU CREATION}

SWAT uses the Hydrological Response Units (HRUs) as the basis for its modeling. HRUs may be formed per subbasin (where a sub-basin is the area that drains into a reach of the stream network), or as a division of a sub-basin based on a particular combination of landuse, soil, and slope range. The Create HRUs form allows users to first select the landuse and soil maps, together with database tables (lookup tables), which relate the categories used in these maps to SWAT landuse and soil categories.

Then users can select intermediate slope percentages so as to form bands of slopes. At this point the maps are read. Then the user can choose singe HRUs (i.e. one per subbasin) or multiple HRUs. In the second case the user removes small HRUs, either by a selecting a minimum area, or by selecting minimal percentages for landuse, soil and slope. Users may optionally also select subbasins at whose exit points reservoirs are situated, may choose to subdivide landuses into others, and may choose to exempt some landuses from the thresholds. In Fig. (5) the main form for HRU generation is shown.

\section{SWAT SETUP AND RUN}

The final step is to read the meteorological data, write the SWAT files in the proper format and run the model. The SWAT Setup and Run form allows the user to select weather sources (currently weather stations, plus precipitation and temperature gauges), to choose the period of simulation, and make a number of other choices as can be seen in Fig. (6).

Users can also choose to make detailed edits to the input files using the SWAT Editor, can run SWAT itself, and can save the output from the latest SWAT run. In brief, this form is the main control of the model itself. It is fully based on the current SWAT development and if required can be modified to keep pace with future changes. Because the entire application is open source, advanced users can even have access to the source code and compile their own DLL for further development.

\section{DISPLAYING SWAT OUTPUT}

Once the model produces the output files, the Swat2Dat tool allows the selection of the desired sub-basin to use and produces ascii files from the SWAT reach output file. This can be directly imported into a spreadsheet for further analysis and plotting. The export tool will be eventually incorporated into the MWSWAT interface. For now it is an independent program that works also for all the different versions of ArcView SWAT. In order to verify the validity of the application, a test watershed (San Juan River in central Mexico) was prepared from scratch for two years of meteorological data. The data used in the present example in the MapWindows tool is from the web data described above. The model output is shown in Fig. (7). The current ArcMap version for SWAT was also tested for a basin with calibration data available. It is worth noticing that both interfaces ultimately run the same and most recent version of the model Swat2005. The results, in the testing basin, are as expected very similar for both platforms with respect to flows. Sediment yield has some differences that are under investigation. Nutrients also behave very similar, but are also under scrutiny. The user lookup tables used are compared to identify potential errors. A further study is in process to validate the output between platforms.

\section{CONCLUSIONS AND FUTURE WORK}

MWSWAT is complete at the time of writing, and will very soon be released. The next immediate technical task is to provide some decision support capability, especially some graphical support for viewing the SWAT outputs. This will certainly include capability for drawing graphs or histograms, especially for comparing outputs from runs with different input parameters, and also for showing, for example, watersheds coloured according to user-chosen characteristics such as sediment output. Another technical aim is to support other kinds of models, such as event-based models which can analyse the effects of storm events.

MWSWAT is the first of, we hope, many tools to support IWRM. The next objective is to form a community of partners who are interested in using and/or contributing tools and other resources to the project. Partner organizations may be government departments, universities and research institutes, or even private companies. In particular partners can provide requirements for new tools and extensions or changes to 
Fig. (4). Delineated Watershed.

Fig. (5). Create HRUs for MWSWAT. 
Fig. (6). SWAT Setup and Run Dialog.

Fig. (7). Example of SWAT Output. 
existing ones. The existence of an active collection of users and developers will also be a critical factor in finding donor organizations to support the project financially.

\section{ACKNOWLEDGMENTS}

The WaterBase project is a project of the United Nations University, International Institute for Software Technology (http://www.iist.unu.edu) and the International Network for Water, Environment and Health (http://www.inweh.unu. edu). We have received collaborative support from the Daniel Ames and the MapWindow team at Idaho State University, from David Tarboton at Utah State University, from Dave Swayne and his group at the University of Guelph, from Karim Abbaspour of Eawag, and, not least, from Raghavan Srinivasan and the SWAT team at Texas A\&M University.

\section{REFERENCES}

Srinivasan R, Arnold JG. Integration of a Basin-Scale Water Quality Model with GIS. Water Resources Bulletin. 1994; Vol. 30; No. 3., Pgs. 453-462.
[2] Neitsch SL, Arnold JG, Kiniry JR, Williams JR. Soil and Water Assessment Tool Theoretical Documentation and User's Manual, Version 2005, GSWR Agricultural Research Service \& Texas Agricultural Experiment Station, Temple Texas, 2005.

[3] OGC, Open Geospatial Consortium, http://www.opengeospatial. org.

[4] OS GIS, Open Source GIS, http://opensourcegis.org/

[5] EPA-Basins: Better Assessment Science Integrating Point and Nonpoint Sources (BASINS). The BASINS home page is http://www.epa.gov/ost/basins.

[6] Tarboton D, Ames DP. Advances in the mapping of flow networks from digital elevation data. In World Water and Environmental Resources Congress. ASCE, May 2001. See http://hydrology.neng. usu.edu/taudem/

[7] SRTM, DEM data from International Centre for Tropical Agriculture (CIAT), available from the CGIAR-CSI SRTM 90m, 2004. Database: http://srtm.csi.cgiar.org.

[8] Hansen M, DeFries R, Townshend J, Sohlberg R. 1 Km Land Cover Classification Derived from AVHRR, 1998. http://glcf.umiacs. umd.edu/ data/landcover.

[9] FAO/UNESCO. Digital Soil Map of the World and Derived Soil Properties. Rev. 1. (CD Rom), 2003. Available from http://www. fao.org/catalog/what_new-e.htm

[10] NCDC, National Climatic Data Center from http://www.ncdc. noaa.gov/oa/mpp/freedata.html 